\title{
Furan Fatty Acid Photooxidative Degradation Products in Dried Herbs and Vegetables
}

\author{
Isabelle A. Sigrist, Giuseppe G.G. Manzardo, and Renato Amadò*
}

\begin{abstract}
The influence of light exposure of dried herbs and vegetables on the formation of dimethyl furan fatty acid (DiMeFFA) photooxidative degradation products such as 2,3-butanedione, 2,3-octanedione, 3-methyl-2,4-nonanedione (MND), 3,4-dimethyl-5-pentyliden-2(5H)-furanone (bovolide) and 3,4-dimethyl-5pentyl-2(5H)-furanone (dihydrobovolide) was investigated. To our knowledge, the occurrence of these compounds in tarragon, dill, basil, chervil, chive, leek, savory and onion has hitherto not been reported. The flavour fraction was isolated by simultaneous distillation extraction and analysed by GC-MS. The flavour compounds were determined in relation to the exposure time as peak area ratio to an internal standard.
\end{abstract}

Keywords: Aroma compounds · Dried herbs · Furan fatty acids · Photooxidation

\section{Introduction}

The first article on furan fatty acids as precursors of flavour compounds was published by Guth and Grosch in 1991 [1]. These authors reported that 3-methyl-2,4nonanedione (MND) is a photooxidative degradation product of dimethyl furan fatty acids (DiMeFFA) and contributes significantly to the light induced off-flavour of soya-bean-oil. Shortly after, Sarelse et al. [2] put forth the hypothesis that two bovolides (3,4-dimethyl-5-pentyliden-2(5H)furanone: bovolide; 3,4-dimethyl-5-pentyl$2(5 \mathrm{H})$-furanone: dihydrobovolide) are formed by photooxidation of DiMeFFA. This was experimentally confirmed by Pompizzi $\overline{{ }^{*} \text { Correspondence: }}$ Prof. Dr. R. Amadò Institute of Food Science and Nutrition Swiss Federal Institute of Technology Schmelzbergstrasse 9

ETH-Zentrum

$\mathrm{CH}-8092$ Zurich

Tel.: + 4116323291

Fax: + 4116321123

E-Mail: renato.amado@ilw.agrl.ethz.ch et al. [3]. Recently, the flavour compounds 2,3-butanedione and 2,3-octanedione were identified in model experiments as additional photooxidative degradation products of DiMeFFA [4]. In the Fig. the five degradation products with flavour characteristics formed by photooxidation of a pentyl DiMeFFA are shown.

MND is an important flavour compound of green tea [5], dry parsley [6] and dry spinach [7] with a straw and hay-like odour [6][7]. In these plant species, 2,3-butanedione was detected as well. Bovolide and dihydrobovolide have been identified in several foodstuffs including dried green parts of plants such as green tea [8], lamb's lettuce, garden cress and woodruff [3] and are flavour compounds with a celery-like odour [9]. The sensory property of 2,3-octanedione is reported to be caramel-like and sweet [10] and sweet and fruity [11], respectively. This diketone, the origin of

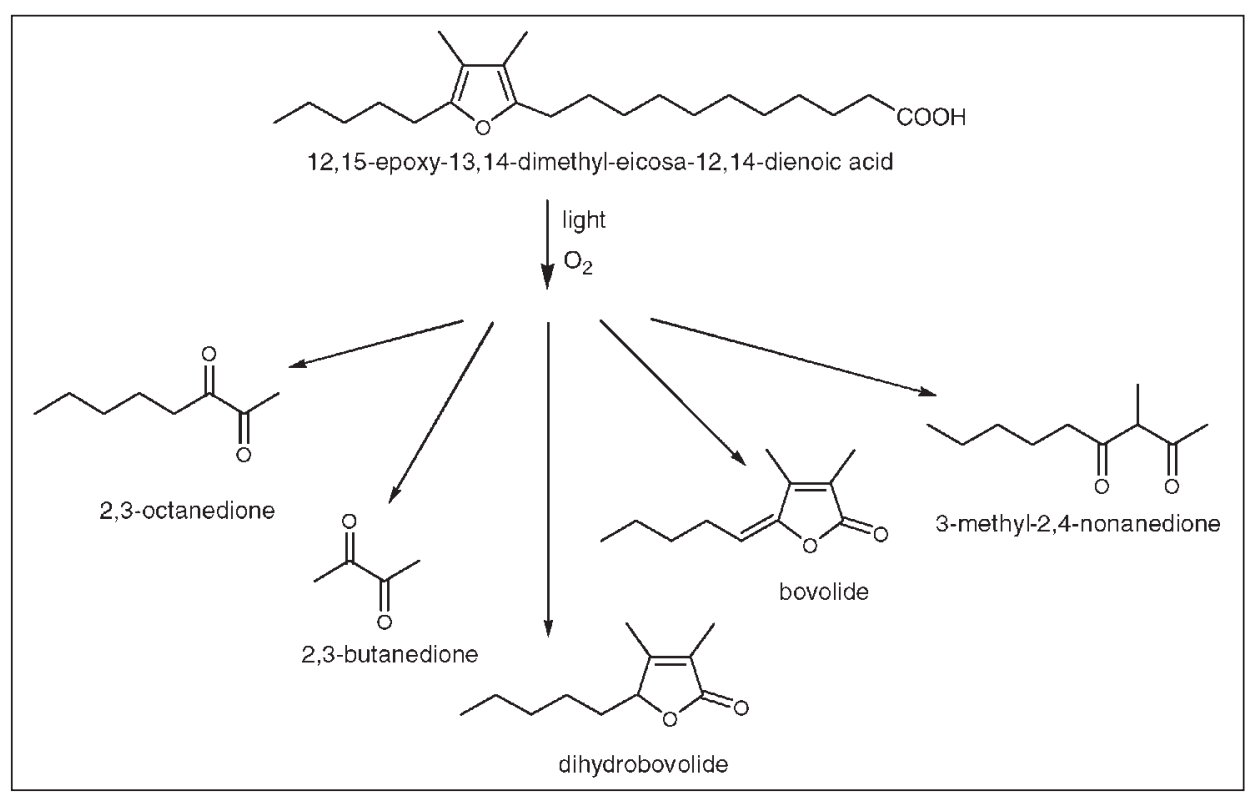

Fig. Photooxidative degradation products of a pentyl diMeFFA 
which puzzled several authors (see e.g. [10][11] and the literature cited therein) was identified for example in beef fat [10], sheep meat [11] and in freshwater fish [12].

In this work, the occurrence of DiMeFFA photooxidative degradation products in different dried plant materials is reported and their relative change after light exposure is investigated.

\section{Experimental}

\section{Food Samples}

Dried samples of tarragon (Artemisia dracunculus), basil (Ocimum basilicum), savory (Satureja hortensis), chervil (Anthriscus cerefolium), dill (Anethum graveolens), chive (Allium schoenoprasum), onion (Allium cepi) and leek (Allium porrum) were obtained from J. Carl Fridlin Gewürze AG (Hünenberg, Switzerland) in paper bags. The samples were stored vacuum-packed in light-protected bags.

\section{Light Exposure of the Food Samples}

The dried samples were packed in transparent PE-film bags filled with compressed air. All samples were exposed to two $36 \mathrm{~W}$ fluorescence lamps (BIOLUX $36^{\circledR}$, Osram AG, Winterthur, Switzerland) at $4500 \mathrm{~lx}$ at room temperature for 4 days. Samples before light exposure were taken as reference.

\section{Extraction of the Volatile Fraction}

Extraction of the volatiles was performed in a micro-steam distillation apparatus (Chrompack 16050, P.H. Staehelin \& Cie. AG, Basel, Switzerland) for $1 \mathrm{~h}(6 \mathrm{~g}$ sample, $80 \mathrm{ml}$ water, $2 \mathrm{ml}$ diethyl ether, $11 \mu \mathrm{g}$ ethyl valerate and $12 \mu \mathrm{g}$ ethyl decanoate as internal standards). The extract was dried $\left(\mathrm{MgSO}_{4}\right)$ and concentrated to $1 \mathrm{ml}$ by means of a Kuderna-Danish concentrator fitted with a Vigreux column at $50{ }^{\circ} \mathrm{C}$.

\section{Gas Chromatography-Mass Spectrometry (GC-MS)}

GC-MS was performed with the column injection technique on a Fisons 8065 gas chromatograph directly coupled to a Finnigan MAT SSQ 710 mass spectrometer. A fused silica SW-10 column (Supelco, $60 \mathrm{~m} \times 0.32 \mathrm{~mm}$ i.d., $0.25 \mu \mathrm{m}$ film thickness) with a deactivated fused silica precolumn $(2.8 \mathrm{~m} \times 0.53 \mathrm{~mm}$ i.d. $)$ was used with helium as carrier gas $(100 \mathrm{kPa})$. The

Table. Changes of the flavour compounds during exposure to light (peak area ratio to the internal standard ethyldecanoate) following temperature programme was used: $40{ }^{\circ} \mathrm{C}$ for $12 \mathrm{~min}, 40^{\circ} \mathrm{C}$ to $240{ }^{\circ} \mathrm{C}$ at $6{ }^{\circ} \mathrm{C} / \mathrm{min}, 240{ }^{\circ} \mathrm{C}$ for $15 \mathrm{~min}$. Electron impact mass spectra were recorded with an ionisation energy of $70 \mathrm{eV}$ in a mass range of 40-440 amu. The compounds were identified by comparison of mass spectra and retention indices (RI, calculated according to Van den Dool and Kratz [13]) with reference substances. For the evaluation of the ratio of the flavour compounds to the internal standard ethyldecanoate, the fragmentions at m/e 86 (2,3-butanedione), 99 (2,3octanedione and MND), 124 (bovolide) and 83 (dihydrobovolide) were used.

\section{Results and Discussion}

The investigated herbs and vegetables have been shown to have varying susceptibility to light exposure (Table); onions were hardly affected at all whereas tarragon, chervil and chive exhibited the most significant changes after illumination. Bovolide was shown to be formed in considerable amounts in almost all samples. It is interesting to note that MND, the most prominent photooxidative degradation product of DiMeFFA, could only be detected either in very small amounts or not at all in the illuminated samples, except for chervil. One reason for this could be that the duration of light exposure used in the present set of experiments ( $4 \mathrm{~d}$ ) was too long. MND could have been formed during the early stages of illumination and reacted further during the later stages. Preliminary results obtained with green tea indicate a decrease of MND after longer illumination times [14]. Another possible explanation can be given considering the amounts of DiMeFFA in the samples. Basil, savory and onion showed to be very low in DiMeFFA with amounts of $7.5 \mu \mathrm{g} / \mathrm{g}$ dry matter and less [15]. Quantitative analysis showed that only $1.3 \%$ of the methyl ester of a DiMeFFA was converted into MND by photooxidation in a model experiment [1]. Therefore the concentration of MND could be below the detection limit. On the other hand, the significant increase of MND in chervil after light exposure corresponds to the high concentration of DiMeFFA of about $100 \mu \mathrm{g} / \mathrm{g}$ dry matter [15]. The poor formation of all flavour compounds in onion could be the result of the comparatively very poor concentration of DiMeFFA $(<0.6 \mu \mathrm{g} / \mathrm{g}$ dry matter [15]) as well as the lack of chlorophyll as sensitiser in the photooxidation.

The present work does not give any indication about the relevance of the oxidation products to the flavour or off-flavour of the investigated herbs and vegetables. Studies related to this question are in progress.

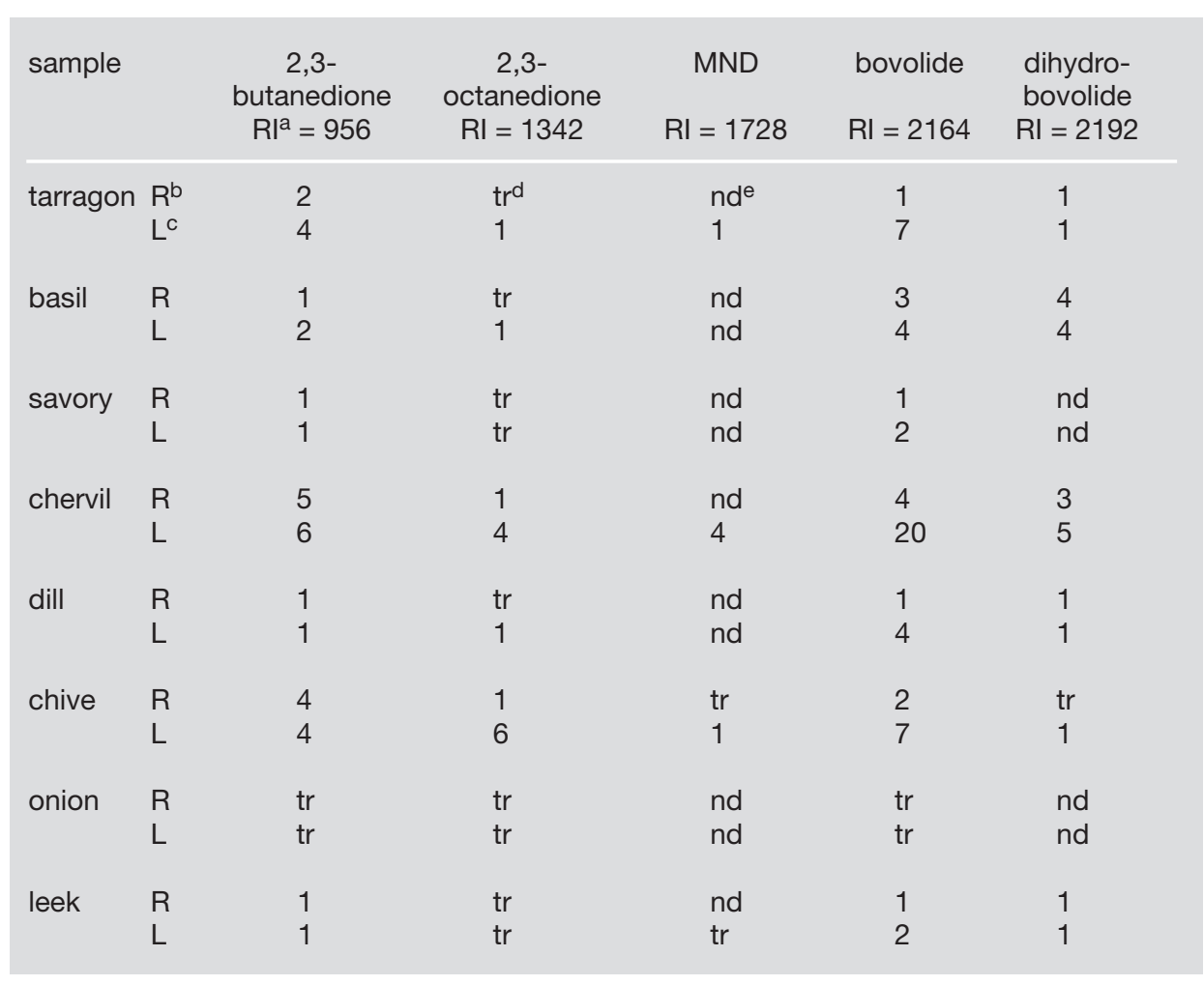

${ }^{a}$ retention index; ${ }^{b}$ reference; ${ }^{c}$ exposed to light $(4 \mathrm{~d}) ;{ }^{d}$ traces; ${ }^{e}$ not detected 


\section{Acknowledgements}

This work was partly supported by MigrosGenossenschafts-Bund Zurich, Switzerland. The herbs and vegetables samples were a gift of J. Carl Fridlin Gewürze AG (Hünenberg, Switzerland). Most of this work has been presented at the conference 'Chemical Reactions in Foods IV' (Prag, September 2000) and has been reprinted with permission of the publisher from Czech J. Food Sci. 2000, 18, 17-19.

Received: May 2, 2002

[1] H. Guth, W. Grosch, Fat. Sci. Technol. 1991, 93, 249.

[2] J.A. Sarelse, K.B. de Roos, C.B. Kanner, P.C. Burgers, J. Kloosterman, in 'Trends in Flavour Research', Eds. H. Maarse, D.G. van der Heij, Elsevier Science, Amsterdam, 1994, p. 373.

[3] R. Pompizzi, M. Lamberti, R. Oechslin,
G.G.G. Manzardo, R. Amadò, in 'Authenticity and Adulteration of Food - the Analytical Approach', Eds. R. Amadò, R. Battaglia, Swiss Society of Food and Environmental Chemistry (SGLUC), Federation of European Chemical Societies, Food Chemistry Division, Winterthur, 1997, p. 472.

[4] R. Pompizzi, 'Furanfettsäuren als Vorläufer von Aromastoffen', ETH-Dissertation Nr. 12129, 1999.

[5] H. Guth, W. Grosch, in 'Progress in Flavour Precursors Studies', Eds. P. Schreier, P. Winterhalter, Allured Publishing Corporation, Carol Stream, 1993, p. 401.

[6] C. Masanetz, W. Grosch, Z. Lebensm. Unters. Forsch. A 1998, 206, 114.

[7] C. Masanetz, H. Guth, W. Grosch, Z. Lebensm. Unters. Forsch. A 1998, 206, 108.
[8] H. Horita, T. Hara, A. Sannai, T. Fujimori, Agric. Biol. Chem. 1985, 49, 3601.

[9] B.D. Mookherjee, R.A. Wilson, Perf. \& Flav. 1990, 15 (Jan./Feb.), 27.

[10] D.K. Larick, H.B. Hedrick, M.E. Bailey, J.E. Williams, D.L. Hancock, G.B. Garner, R.E. Morrow, J. Food Sci. 1987, 52, 245.

[11] O.A. Young, J.-L. Berdagué, C. Viallon, S. Rousset-Akrim, M. Theriez, Meat Sci. 1997, 45, 183 .

[12] D.B. Josephson, R.C. Lindsay, D.A. Stuiber, J. Agric. Food Chem. 1984, 32, 1344.

[13] H. Van den Dool, P.D. Kratz, J. Chromatog. 1962, 11, 463.

[14] I.A. Sigrist, ETH Dissertation, in preparation

[15] I.A. Sigrist, G.G.G. Manzardo, R. Amadò, in 'Biologically-active Phytochemicals in Food', Eds. W. Pfannhauser, G.R. Fenwick, S. Khokhar, Royal Society of Chemistry, Cambridge, 2001, p. 237.

\title{
Continuous Evolved Gas Analysis and Thermal Analysis in Micro-scale Roasting of Foods
}

\author{
Rainer Perren*, Roland Künzli, and Felix Escher
}

\begin{abstract}
In roasting processes of foods, non-enzymatic browning reactions lead to the formation of water and carbon dioxide. Continuous monitoring of the evolution of moisture and carbon dioxide would offer an interesting tool for determining reaction kinetics of non-enzymatic browning and optimising roasting processes. Isothermal and dynamic heating of small specimens of hazelnuts in a differential scanning calorimeter which was linked to a non-dispersive IR gas analyser presents a possibility to simulate roasting processes on a micro-scale. Formation of water and carbon dioxide was dependant on the initial moisture content of the hazelnuts, heating rate and composition of gas atmosphere (nitrogen vs. oxygen). Depending on the heating conditions, evolution of carbon dioxide is not only caused by degradation of amino acids and sugars but also by lipid oxidation.
\end{abstract}

Keywords: Evolved gas analysis · Lipid oxidation · Non-enzymatic browning · Roasting of foods · Thermal analysis

${ }^{\star}$ Correspondence: Dr. R. Perren

Institute of Food Science and Nutrition

ETH-Zentrum

$\mathrm{CH}-8092$ Zürich

Tel: : +4116327975

Fax: +4116321123

E-Mail: rainer.perren@ilw.agrl.ethz.ch

www.ethz.ch

\section{Introduction}

Roasting of nuts, cocoa, coffee etc. is carried out to develop flavour components from sugars and amino acids by the nonenzymatic browning reaction at increased temperatures. Thereby, the moisture content is decreased to below $1 \%$ and a crisp texture is developed. Non-enzymatic browing reactions at roasting temperatures of
120-200 ${ }^{\circ} \mathrm{C}$ lead to the formation of flavour and colour compounds as well as to the evolution of water and carbon dioxide [1][2]. In addition to the decarboxylation of amino acids during the Strecker degradation, carbon dioxide is formed by thermal degradation of sugars and ascorbic acid, and also by lipid oxidation [3]. Finally, pyrolysis and combustion of organic material occur at elevated temperatures. As long as a sufficient 